\title{
Frekuensi Antenatal Care Tidak Berhubungan dengan Tingkat Pengetahuan Perawatan Kesehatan pada Ibu Nifas
}

\author{
Fatimatasari ${ }^{1}$, Ashon Sa'adi², Widati Fatmaningrum $^{2}$ \\ ${ }^{1}$ Universitas Alma Ata Yogyakarta \\ Jalan Ringroad Barat Daya No.1, Tamantirto, Yogyakarta, Indonesia \\ ${ }^{2}$ Program Studi Pendidikan Bidan Fakultas Kedokteran Universitas Airlangga, Indonesia \\ Jalan Mayjen Prof. Dr. Moestopo 47, Pacar Kembang, Surabaya, Jawa Timur 60132, Indonesia \\ Email: fatimatasari@gmail.com
}

\begin{abstract}
Abstrak
Pengetahuan perawatan kesehatan ibu berhubungan dengan perilaku perawatan kesehatan dan hasil luaran kehamilan. Antenatal care adalah salah satu kesempatan untuk meningkatkan pengetahuan tentang perawatan kesehatan ibu. Tujuan penelitian adalah untuk mengetahui hubungan frekuensi ANC dengan tingkat pengetahuan perawatan kesehatan ibu pada ibu nifas di RSUD Majenang. Penelitian ini menggunakan rancangan cross sectional. Sampel dalam penelitian ini adalah 35 ibu nifas yang dirawat di RSUD Majenang tangal 12 Mei hingga 12 Juni 2016 yang memiliki kriteria ibu yang masih dalam masa nifas, usia kehamilan terakhir aterm (>37 minggu), dapat menunjukkan buku KIA, pendidikan terakhir maksimal SMA dan melakukan ANC dengan dokter spesialis kebidanan dan kandungan maksimal 2 kali selama hamil. frekuensi ANC dinilai dari kuesioner dan catatan kunjungan ANC pada buku KIA. Tingkat pengetahuan perawatan kesehatan ibu dinilai dengan kuesioner dan panduan wawancara Hasil penelitian menunjukkan 62,9\% responden melakukan frekuensi ANC baik, 28,6\% cukup dan 8,6\% kurang pada kehamilan terakhir. 57,1\% responden memiliki tingkat perawatan kesehatan ibu sedang, 31,4\% kurang dan 11,4\% baik. Hasil uji Spearman Rank hubungan frekuensi ANC dan tingkat perawatan kesehatan ibu dengan dengan derajat kemaknaan $\alpha=0,05$ menunjukkan $p$-value=0,293, artinya tidak ada hubungan yang bermakna antara frekuensi ANC dengan tingkat pengetahuan perawatan kesehatan ibu pada ibu nifas di RSUD Majenang. Kesimpulan tidak adanya hubungan yang bermakna antara frekuensi ANC dengan tingkat pengetahuan perawatan kesehatan ibu pada ibu nifas di RSUD Majenang dikarenakan banyak faktor yang memengaruhi yaitu sumber informasi yang beragam, materi pendidikan kesehatan yang tidak adekuat pda saat ANC, sikap responden terhadap informasi yang diberikan bidan dan belum adanya pengawasan pemerintah terhadap mutu pelayanan ANC terutama terhadap praktik KIE.
\end{abstract}

Kata Kunci: frekuensi ANC, tingkat pengetahuan perawatan kesehatan ibu

\section{Frequency of Antenatal Care Had No Relation with the Level of Maternal Health Care Knowledge for Postpartum Mother}

\begin{abstract}
Maternal health care knowledge affects prenatal care and pregnanci's outcome. Antenatal care is one opportunity to increase maternal health care knowledge. This study aims to investigate the association between antenatal care visits and level of maternal health knowledge among postpartum women in RSUD Majenang. This study was a cross sectional design. The sample was thirty five Postpartum women who admitted in RSUD Majenang on $12^{\text {th }}$ May to $12^{\text {th }}$ June with criteria: being on post partum period, had aterm pregnancy, could show KIA books, had maximally senior high school graduated and performed antenatal care with obstetric and gynecologist maximally twice during pregnancy. Antenatal care visits assessed by questionnaire and antenatal visits record in KIA book. Level of maternal health care knowledge was assessed by questionnaire and interview. This study found $62.9 \%$ of total respondents had good antenatal care visits, $28.6 \%$ moderate and $8.6 \%$ had less antenatal care visits during last pregnancy. $57.1 \%$ of total respondents had moderate maternal health care knowledge, $31.4 \%$ less and $11.4 \%$ had good maternal healthcare knowledge. Spearman Rank
\end{abstract}


test with the significance level $\alpha=0.05$ showed $p$ value $=0,293$, it means there is no significant association between antenatal care visits and level of maternal health care knowledge. Conclusion, the un significant association between antenatal care visits level of maternal health care knowledge among postpartum women in RSUD Majenang may caused by many factors, such as the respondents belief about maternal health care information, diverse information resources, insufficient education materials from health care providers and lack of anteatal care quality assessment from health ministry.

Keywords: antenatal care visits, the level of maternal health care knowledge

Info Artikel:

Artikel dikirim pada 22 Maret 2017

Artikel direvisi pada 30 Mei 2017

Artikel diterima pada 13 September 2017

DOI : http://dx.doi.org/10.21927/jnki.2017.5(2).100-105

\section{PENDAHULUAN}

Pengetahuan perawatan kesehatan ibu didefinisikan sebagai keterampilan kognitif yang menentukan kemampuan seorang wanita untuk meningkatkan dan mempertahankan kesehatan diri mereka dan kesehatan anak-anak mereka (1). Beberapa penelitian memperlihatkan adanya hubungan yang signifikan antara pengetahuan perawatan kesehatan ibu dengan perilaku perawatan kesehatan ibu dan hasil luaran kehamilan. Beberapa penelitian tersebut menunjukkan adanya hubungan yang signifikan antara pengetahuan perawatan kesehatan ibu dengan frekuensi pemeriksaan kehamilan, kadar hematocrit dan penambahan berat badan yang adekuat pada akhir kehamilan, penurunan kejadian bayi prematur, bayi berat lahir rendah (BBLR) serta bayi meninggal $(2,3)$. Salah satu kesempatan untuk meningkatkan pengetahuan tentang perawatan kesehatan ibu adalah melalui Antenatal Care (ANC) (4). Upaya pendidikan kesehatan yang dilakukan didalam ANC meliputi kegiatan Konseling Informasi dan Edukasi (KIE) tentang isu-isu penting yang dapat memengaruhi kesehatan kehamilan, ibu dan bayi. Hasil Assesmen Kualitas Pelayanan Maternal tahun 2012, menunjukkan hanya $24 \%$ rumah sakit dan $45 \%$ puskesmas yang melakukan konseling dan edukasi sesuai standar pada saat melakukan pelayanan ANC. Hasil riset kesehatan dasar (Riskesdas) tahun 2010 memperlihatkan 58\% ibu hamil di Indonesia melaporkan tidak mendapatkan penjelasan tentang tanda bahaya kehamilan dari petugas kesehatan pada saat ANC $(5,6)$. Dalam suatu penelitian disebutkan bahwa kurangnya pemberian penjelasan kepada ibu hamil tentang hal-hal yang berkaitan dengan perawatan kehamilan dan persalinan disebabkan karena tidak ada waktu yang cukup untuk memberikan penjelasan tentang hal tersebut dimana umumnya bidan memberikan pelayanan dalam waktu kurang dari 10 menit (7). Penelitian ini bertujuan untuk menganalisis hubungan antara frekuensi ANC dengan tingkat pengetahuan perawatan kesehatan ibu.

\section{BAHAN DAN METODE}

Penelitian ini dilakukan di ruang nifas RSUD Majenang yang berlokasi di JI. Dr. Soetomo nomor 5 Majenang. Desain penelitian menggunakan cross sectional. Populasi penelitian adalah seluruh ibu nifas yang dirawat di RSUD Majenang. Teknik sampling yang digunakan adalah aksidental sampling dengan kriteria inklusi yaitu ibu yang masih dalam masa nifas dan dapat menunjukkan buku KIA. Kriteria eksklusi adalah ibu yang memiliki riwayat kehamilan terakhir preterm, memiliki tingkat pendidikan perguruan tinggi atau sederajat, dan melakukan ANC di tempat praktik dokter lebih dari dua kali selama hamil. Jumlah sampel dalam penelitian ini sebanyak 35 orang, yaitu ibu-ibu nifas yang berhasil ditemui peneliti di ruang nifas RSUD Majenang yang memiliki kriteria tersebut dari tanggal 12 Mei-12 Juni 2015. Pengumpulan data menggunakan kuesioner, buku KIA dan panduan wawancara. Tingkat frekuensi dinilai dari jumlah kunjungan ANC selama kehamilan terakhir berdasarkan keterangan dari responden dan catatan kunjungan pada buku KIA. Frekuensi ANC dikategorikan menjadi baik apabila jumlah kunjungan ANC 4 kali atau lebih dengan jadwal sesuai standar pemerintah, yaitu minimal 1 kali pada trimester I, minimal 1 kali pada trimester II dan minimal 2 kali pada trimester III. Dikatakan cukup bila jumlah kunjungan ANC 4 kali atau lebih tetapi dengan jadwal yang tidak sesuai dengan standar pemerintah, dan dikatakan 
kurang bila jumlah kunjungan ANC kurang dari 4 kali. Tingkat pengetahuan perawatan kesehatan ibu dinilai dari jawaban responden terhadap pertanyaan tentang perawatan kesehatan ibu yang ada dalam materi pokok KIE dalam buku Pedoman Antenatal Terpadu 2010 yang terdiri dari 12 macam pengetahuan meliputi Keluarga Berencana (KB), tablet tambah darah (TTD), ASI eksklusif dan IMD, persiapan menghadapi kondisi gawat darurat, tanda bahaya kehamilan, istirahat dalam kehamilan, gizi ibu hamil, pekerjaan pada masa hamil, PHBS dalam kehamilan, dan peningkatan intelegensia dalam kehamilan (brain booster) dan jadwal pemeriksaan kehamilan yang dianjurkan. Tingkat pengetahuan responden dikatakan baik jika nilai responden $76-100$, sedang jika nilai responden 56-75 dan kurang jika nilai responden kurang dari 56. Analisis data pada penelitian ini yaitu analisis univariat untuk menghasilkan persentase dari setiap variable. Analisis bivariat untuk menganalisis hubungan frekuensi ANC dengan tingkat pengetahuan perawatan kesehatan ibu menggunakan uji Spearman rank, dimana kedua variabel merupakan variabel dengan skala ordinal.

\section{HASIL DAN BAHASAN}

Responden dalam penelitian ini sebagian besar berada pada usia reproduksi sehat (20-35 tahun) yaitu sebanyak 27 orang $(77,2 \%)$ dan 8 orang berada pada usia resiko tinggi terdiri dari 4 orang berumur kurang dari 20 tahun dan 4 orang berumur lebih dari 35 tahun. Sebagian besar responden memiliki paritas (jumlah frekuensi melahirkan) 1 yaitu sebanyak 16 orang $(45,7 \%)$ dan terdapat responden yang berstatus paritas risiko tinggi (paritas lebih dari 4$)$ yaitu sebanyak 2 orang $(5,8 \%)$. Selain itu, pendidikan terakhir responden sebagian besar adalah SMP yaitu sebanyak 16 orang $(45,7 \%)$ dan mayoritas berpenghasilan rendah yaitu sebanyak 25 orang (71,4\%).

Tempat yang paling sering dikunjungi untuk melakukan ANC adalah Bidan Praktik Mandiri (BPM) (74,3\%), sedangkan jumlah responden yang memiliki akses informasi mengenai perawatan kesehatan ibu, selain dari bidan pemberi ANC, yaitu dari penyuluhan, konsultasi dokter spesialis kebidanan dan kandungan, majalah dan internet, ialah sebanyak 10 responden $(27,0 \%)$.

Hasil penelitian menunjukkan sebagian besar responden memiliki tingkat frekuensi ANC baik dan tingkat pengetahuan tentang perawatan kesehatan
Tabel 1. Karakteristik Responden

\begin{tabular}{lcc}
\hline \multicolumn{1}{c}{ Karakteristik } & $\mathbf{n}$ & $\mathbf{\%}$ \\
\hline Umur & & \\
$\quad<20$ tahun & 4 & 11,4 \\
20-35 tahun & 27 & 77,2 \\
$\quad$ 35 tahun & 4 & 11,4 \\
Paritas & & \\
$\quad$ Paritas 1 & 16 & 45,7 \\
$\quad$ Paritas 2 & 13 & 37,1 \\
$\quad$ Paritas 3 & 4 & 11,4 \\
$\quad$ Paritas 4 & 0 & 0 \\
$\quad$ Paritas >4 & 2 & 5,8 \\
Pendidikan & & \\
$\quad$ SD & 13 & 37,1 \\
$\quad$ SMP & 16 & 45,7 \\
SMA & 6 & 17,2 \\
Penghasilan & & \\
$\quad$ R Rp 1.100.000 & 25 & 71,4 \\
$\quad$ Rp1.100.000 - Rp 2.200.000 & 10 & 28,6 \\
Tempat paling sering melakukan ANC & & \\
$\quad$ BPM & 26 & 74,3 \\
Puskesmas & 5 & 14,3 \\
Posyandu & 4 & 11,4 \\
Sumber informasi perawatan kesehatan ibu & & \\
$\quad$ Bidan pemberi ANC saja & 25 & 71,4 \\
Sumber lain seperti kelas ibu hamil, & 10 & 28,6 \\
internet, majalah, dan konsultasi & & \\
dengan tenaga kesehatan lain & & \\
Total & 35 & $\mathbf{1 0 0}$ \\
\hline
\end{tabular}

Sumber: Data Primer Tahun 2015

ibu sedang. Sedangkan, uji hubungan antara dua variable tersebut menunjukkan tidak ada hubungan yang bermakna antara tingkat frekuensi ANC responden dengan tingkat pengetahuan mereka tentang perawatan kesehatan ibu.

Tabel 2. Tingkat Frekuensi Antenatal Care Responden

\begin{tabular}{lcc}
\hline Tingkat Frekuensi ANC & $\mathbf{n}$ & $\mathbf{\%}$ \\
\hline Baik & 22 & 62,9 \\
Cukup & 10 & 28,6 \\
Kurang & 3 & 8,6 \\
Total & 35 & 100 \\
\hline
\end{tabular}

Sumber: Data Primer Tahun 2015

Berdasarkan Tabel 2 memperlihatkan bahwa $62,9 \%$ responden memiliki tingkat frekuensi ANC yang baik, $28,6 \%$ cukup dan $8,6 \%$ kurang. Berdasarkan keterangan responden, sepuluh responden yang melakukan ANC dengan jumlah cukup semuanya melewatkan kunjungan K1. Sebagian responden mengatakan tidak melakukan kunjungan ANC pada trimester I karena tidak mengetahui kehamilannya, 
sedangkan sebagian yang lain mengatakan karena memiliki pekerjaan yang tidak bisa ditinggalkan sehingga harus menunda ANC. Berdasarkan keterangan responden, tiga orang yang melakukan ANC kurang dari 4 kali selama hamil mengatakan, satu diantaranya karena kehamilannya tidak direcanakan, satu karena menganggap ANC hanya perlu dilakukan jika ada keluhan dan satu lainnya karena keterbatasan biaya. Hal ini sesuai dengan teori, bahwa frekuensi ANC dipengaruhi oleh status kehamilan, pegetahuan tentang ANC dan status ekonomi (8-10).

Tabel 3. Tingkat Pengetahuan Responden tentang Perawatan Kesehatan Ibu

\begin{tabular}{lcc}
\hline $\begin{array}{c}\text { Tingkat Pengetahuan } \\
\text { Perawatan Kesehatan Ibu }\end{array}$ & n & \% \\
\hline Baik & 4 & 11,4 \\
Sedang & 20 & 57,1 \\
Kurang & 11 & 31,4 \\
Total & 35 & 100,0 \\
\hline
\end{tabular}

Sumber: Data Primer Tahun 2015

Berdasarkan Tabel 3 menunjukkan bahwa sebagian besar responden memiliki pengetahuan sedang, sedangkan responden yang memiliki pengetahuan baik hanya $11,4 \%$. Dari hasil jawaban responden terhadap seluruh pertanyaan kuesioner didapatkan bahwa pertanyaan yang banyak dijawab secara benar oleh responden ialah pertanyaan tentang jarak yang aman untuk merencanakan kehamilan berikutnya $(100 \%)$, jadwal pemeriksaan kehamilan minimal yang harus dilakukan selama hamil $(94,2 \%)$, hal-hal yang perlu dipersiapkan apabila menghadapi kondisi gawat darurat $(80 \%)$, mengetahui gejala penyakit yang dapat membahayakan kehamilan $(80 \%)$, dan cara meningkatkan kecerdasan bayi sejak di dalam kandungan $(85,7 \%)$. Sedangkan, pertanyaan yang sedikit dijawab secara benar yaitu pertanyaan tentang tanda bahaya dan tanda normal dalam kehamilan (48,6\%), jumlah dan cara meminum tablet tambah darah TTD yang benar (42,9\%), makanan yang boleh dan yang harus dihindari pada saat hamil $(25,7 \%)$, jenis pekerjaan yang boleh dan yang harus dihindari pada saat hamil $(42,9 \%)$, dan cara yang tepat untuk menjaga kebersihan khususnya daerah kewanitaan pada saat hamil (40\%).

Pertanyaan kuesioner dalam penelitian ini ialah pertanyaan tentang perawatan kesehatan ibu yang diambil dari materi KIE pada pedoman ANC terpadu 2010. Dalam pedoman ini pemerintah mengitegrasikan pemberian informasi tentang perawatan kesehatan ibu dengan pelayanan ANC dengan tujuan agar ibu hamil dapat terpenuhi kebutuhannya akan informasi tersebut secara komplit. Masih sedikitnya responden yang memiliki tingkat pengetahuan tentang perawatan kesehatan ibu yang baik dalam penelitian ini menunjukkan bahwa upaya pemerintah untuk memenuhi kebutuhan ibu tentang informasi perawatan kesehatan melalui KIE pada saat ANC tersebut belum berhasil.

Tabel 4. Analisis Hubungan Frekuensi ANC dengan Tingkat Pengetahuan Perawatan Kesehatan Ibu

\begin{tabular}{lccccc}
\hline \multirow{2}{*}{$\begin{array}{c}\text { Frekuensi } \\
\text { ANC }\end{array}$} & \multicolumn{3}{c}{ Tingkat Pengetahuan } & \multirow{2}{*}{ Jumlah } & \multirow{2}{*}{ p-value } \\
\cline { 2 - 5 } & Baik & Cukup & Kurang & & \\
\hline Baik & 3 & 10 & 9 & 22 & \\
Cukup & 1 & 7 & 2 & 10 & 0,293 \\
Kurang & 0 & 3 & 0 & 3 & \\
Total & 4 & 20 & 11 & 35 & \\
\hline
\end{tabular}

Sumber: Data Primer Tahun 2015

Berdasarkan Tabel 4 memperlihatkan $p$-value $>\alpha$, maka dapat disimpulkan bahwa tidak ada hubungan yang bermakna antara tingkat frekuensi ANC dengan tingkat pengetahuan perawatan kesehatan ibu pada ibu nifas di RSUD Majenang. Artinya, banyaknya kunjungan ANC selama hamil tidak mempengaruhi tingkat pengetahuan responden tentang perawatan kesehatan ibu. Penelitian ini menunjukkan hasil yang berbeda dengan penelitian Perumal et al yang menyimpulkan bahwa ada hubungan yang positif antara frekuensi kunjungan ANC dengan skor tingkat pengetahuan tentang perawatan kesehatan ibu (11). Perbedaan ini dikarenakan dalam penelitian tersebut dilakukan kontrol terhadap faktor-faktor perancu hubungan ANC dengan pengetahuan responden seperti usia, usia kehamilan, status perkawinan, tingkat pendidikan dan keterlibatan dalam kegiatan menghasilkan pendapatan dimana hal tersebut tidak dilakukan dalam penelitian ini.

Hasil tabulasi silang antara tingkat frekuensi ANC dengan tingkat pengetahuan perawatan kesehatan ibu menunjukkan bahwa dari 3 responden yang melakukan kunjungan ANC dengan frekuensi kurang, ketiganya memiliki tingkat pengetahuan perawatan kesehatan ibu pada tingkatan sedang. Sedangkan dari 22 responden yang melakukan kunjungan ANC dengan frekuensi yang baik, terdapat 3 responden yang memiliki tingkat pengetahuan perawatan kesehatan ibu baik. Hal ini menunjukkan bahwa frekuensi ANC yang kurang 
tidak menyebabkan tingkat pengetahuan ibu tentang perawatan kesehatan menjadi kurang, dan frekuensi ANC yang baik tidak menyebabkan tingkat pengetahuan menjadi baik.

Belajar adalah proses perubahan perilaku melalui pengalaman, baik pengalaman langsung maupun tidak langsung, dimana pengalaman tersebut dapat diperoleh melalui proses perbuatan atau mengalami sendiri, proses mengamati dan mendengarkan melalui media tertentu, atau proses mendengarkan melalui bahasa KIE yang diberikan pada saat ANC adalah salah satu proses belajar dan bukan satu-satunya proses belajar yang membentuk pengetahuan responden tentang perawatan kesehatan ibu (12). Sebagai salah satu contoh, berdasarkan keterangan dari salah satu responden, responden mengatakan mengetahui bahwa pekerjaan yang mengharuskan berdiri terus menerus tidak baik dilakukan oleh ibu hamil, karena berdasarkan pengalamannya bekerja di pabrik dengan pekerjaan demikian membuat peredaran darahnya tidak lancar dan menurutnya tidak baik jika dilakukan oleh ibu hamil. Contoh yang lain, salah satu responden mengatakan mengetahui bahwa ibu hamil tidak boleh menggunakan sabun khusus daerah kewanitaan karena diberitahu oleh ibu responden. Kriteria sampel dalam penelitian ini juga tidak dibatasi paritas pertama, sehingga ada kemungkinan responden telah mendapatkan pengetahuan tersebut dari ANC kehamilan sebelumnya. Oleh karena itu, frekuensi ANC yang kurang tidak menyebabkan pengetahuan mereka tentang perawatan kesehatan ibu menjadi kurang pula.

Penelitian ini juga menunjukkan bahwa frekuensi ANC yang baik tidak menyebabkan tingkat pengetahuan tentang perawatan kesehatan ibu menjadi baik pula. Dengan kata lain, proses pendidikan kesehatan pada saat ANC belum berhasil untuk meningkatkan pengetahuan responden tentang perawatan kesehatan ibu. Menurut Guilbert yang dikutip Notoatmodjo, ada 4 faktor yang mempengaruhi proses belajar, yaitu faktor instrumental, subjek belajar, materi dan lingkungan (12). Termasuk kedalam faktor instrumental adalah pengajar, dalam hal ini pengajar ialah bidan pemberi ANC. Berdasarkan hasil wawancara, sebagian responden mengatakan bahwa bidan pemberi ANC tidak memberikan KIE, yaitu terutama bidan yang bertugas di Posyandu dan Puskesmas. Responden mengatakan hal itu terjadi karena banyak pasien yang mengantri sehingga pemeriksaan dilakukan dengan cepat dan seringkali bidan hanya memeriksa saja tanpa memberikan $\mathrm{KIE}$. Sebagian responden yang lain mengatakan bahwa bidan memberikan KIE tetapi materi yang diberikan tidak adekuat. Terbukti bahwa hampir seluruh responden mengatakan pada saat ANC diberi informasi tentang pekerjaan yang baik selama hamil, namun hanya sebagian kecil responden yang mengetahui bahwa pekerjaan yang mengharuskan berdiri terlalu lama termasuk kedalam pekerjaan yang tidak boleh dilakukan oleh ibu hamil. Hampir seluruh responden mengatakan diberi nasihat tentang makanan yang baik untuk ibu hamil, namun hanya sebagian kecil responden yang mengetahui bahwa daging yang diamasak setengah matang termasuk makanan yang tidak boleh dimakan oleh ibu hamil.

Termasuk kedalam faktor subjek belajar adalah sikap responden. Berdasarkan hasil wawancara dengan responden, hampir seluruh responden mengatakan diberitahu bidan bahwa ibu hamil tidak memiliki pantangan makanan, namun sebagian besar responden mengatakan ibu hamil tidak boleh memakan daging kambing. Hal ini menunjukkan bahwa responden lebih meyakini informasi yang mereka dapatkan dari orang-orang yang terdekat dengan mereka daripada informasi dari bidan.

Termasuk kedalam faktor lingkungan adalah kebijakan pemerintah. Belum ada pengawasan pemerintah terhadap mutu pelayanan ANC yang diberikan oleh petugas kesehatan, terutama terhadap praktik pemberian KIE pada saat ANC. Hal ini terbukti dengan banyak petugas kesehatan yang tidak memberikan KIE sesuai standar pada saat ANC. Pemerintah juga belum melakukan evaluasi terhadap hasil pemberian KIE tersebut. Hal ini terbukti dengan belum ada laporan nasional tentang tingkat pengetahuan perawatan kesehatan ibu sebagai bahan evaluasi.

\section{SIMPULAN DAN SARAN}

Tidak terdapat hubungan yang bermakna antara frekuensi ANC dengan tingkat pengetahuan perawatan kesehatan ibu pada ibu nifas di RSUD Majenang. Tidak adanya hubungan yang bermakna ini kemungkinan disebabkan oleh banyak hal, diantaranya karena sumber informasi yang diperoleh responden tentang perawatan kesehatan ibu tidak hanya berasal dari petugas ANC pada kehamilan terakhir saja, responden lebih meyakini mitos atau 
nasihat orang-orang terdekat daripada informasi dari petugas ANC, dan pemberian materi KIE oleh petugas ANC masih belum adekuat yang dikarenakan tidak adanya pengawasan dari pemerintah terkait kualitas layanan ANC yang diberikan oleh petugas.

Pada penelitian selanjutnya sebaiknya pengambilan sampel diambil lebih homogen, atau dilakukan kontrol terhadap variabel-variabel perancu sehingga hasil analisisnya lebih baik. Perlu penelitian lebih lanjut tentang proses pemberian KIE pada saat ANC dan kualitas petugas pemberi ANC.

\section{RUJUKAN}

1. Mojoyinola J. Influence of Maternal Health Literacy on Healthy Pregnancy and Pregnancy Outcomes of Women Attending Public Hospitals in Ibadan, Oyo State, Nigeria. African Res Rev [Internet]. 2011 Jun 22;5(3):28-39. Available from: http://www.ajol.info/index.php/afrrev/article/ view/67336

2. Kohan S, Ghasemi S, Dodangeh M. Associations between maternal health literacy and prenatal care and pregnancy outcome. Iran J Nurs Midwifery Res Autumn [Internet]. 2007 [cited 2017 Apr 3];12(4):146-52. Available from: http://ijnmr. mui.ac.ir/index.php/ijnmr/article/viewFile/31/31

3. Ohnishi M, Nakamura K, Takano T. Improvement in maternal health literacy among pregnant women who did not complete compulsory education: policy implications for community care services. Health Policy [Internet]. 2005 May;72(2):157-64. Available from: http://www.ncbi.nlm.nih.gov/ pubmed/15802151

4. KAWASAKI R, ITO H, OHNISHI M. Factors associated with maternal health knowledge through community-based antenatal care program among pregnant women in rural Paraguay. Japanese $\mathrm{J}$ Heal Hum Ecol [Internet]. 2014;80(5):215-24. Available from: http://jlc.jst.go.jp/DN/JST.JSTAGE/ jshhe/80.215?lang=en\&from=CrossRef\&type $=a b$ stract
5. Kementerian Kesehatan Republik Indonesia Direktorat Jenderal Bina Gizi dan KIA. Rencana Aksi Percepatan Penurunan Angka Kematian Ibu di Indonesia. Jakarta: Kementerian Kesehatan Republik Indonesia Direktorat Jenderal Bina Gizi dan KIA; 2013.

6. Kementrian Kesehatan Republik Indonesia. Profil Kesehatan Indonesia tahun 2013. Jakarta: Kementrian Kesehatan RI; 2014.

7. Arifin A. Persepsi ibu hamil tentang Antenatal Care dan persalinan. Bul Penelit Sist Kesehat. 2005;8(2):84-9.

8. Gupta S, Yamada G, Mpembeni R, Frumence G, Callaghan-Koru JA, Stevenson R, et al. Factors associated with four or more antenatal care visits and its decline among pregnant women in Tanzania between 1999 and 2010. PLoS One [Internet]. 2014;9(7):e101893. Available from: http://www.ncbi.nlm.nih.gov/pubmed/25036291

9. Ye Y, Yoshida Y, Harun-Or-Rashid M, Sakamoto J. Factors affecting the utilization of antenatal care services among women in Kham District, Xiengkhouang province, Lao PDR. Nagoya J Med Sci [Internet]. 2010 Feb;72(1-2):23-33. Available from: http://www.ncbi.nlm.nih.gov/ pubmed/20229700

10. Zhao Q, Kulane A, Gao Y, Xu B. Knowledge and attitude on maternal health care among rural-tourban migrant women in Shanghai, China. BMC Womens Health [Internet]. 2009 Mar 20;9:5. Available from: http://www.ncbi.nlm.nih.gov/ pubmed/19298681

11. Perumal N, Cole DC, Ouédraogo HZ, Sindi $\mathrm{K}$, Loechl C, Low J, et al. Health and nutrition knowledge, attitudes and practices of pregnant women attending and not-attending ANC clinics in Western Kenya: a cross-sectional analysis. BMC Pregnancy Childbirth [Internet]. 2013 Jul 11;13:146. Available from: http://www.ncbi.nlm. nih.gov/pubmed/23845074

12. Notoatmodjo S. Perilaku Kesehatan dan Promosi Kesehatan. Jakarta: Rineka Cipta; 2012. 